Andrea Ferreira Leite ${ }^{a}$

Júlia Aparecida Devidé Nogueira ${ }^{\mathrm{a}}$

Universidade de Brasília (UnB). Faculdade de Educação Física. Brasília, DF, Brasil.

Contato:

Andrea Ferreira Leite

E-mail:

afleite78@gmail.com

Trabalho baseado em dissertação de mestrado de Andrea Ferreira Leite intitulada Saúde relacionada ao contexto de trabalho, ao autocuidado apoiado e ao cuidar de si em professores universitários de educação física, defendida em 2016 no Programa de Pós-Graduação em Educação Física da Universidade de Brasília.

Os autores declaram que não houve financiamento para a pesquisa, que não há conflitos de interesses e que o trabalho não foi apresentado em eventos científicos.

\section{Fatores condicionantes de saúde relacionados ao trabalho de professores universitários da área da saúde: uma revisão integrativa}

\author{
Health conditioning factors work-related to health professors: \\ an integrative review
}

\section{Resumo}

Objetivo: sistematizar estudos que abordam o tema da saúde dos professores universitários da grande área da saúde e os fatores ocupacionais condicionantes e determinantes de saúde associados, e realizar uma reflexão sobre o tema. Métodos: revisão integrativa descritiva e analítica realizada em bases bibliográficas eletrônicas brasileiras e internacionais, baseada em estudos publicados em português e inglês entre janeiro de 2005 e março de 2016. Resultados: as buscas e as aplicações dos critérios de seleção resultaram na inclusão de vinte estudos (três teses, cinco dissertações e doze artigos). No geral, os estudos apontam que os docentes identificam como aspectos negativos à saúde as condições físicas e psicológicas de trabalho e, como aspectos promotores da saúde, a satisfação com a profissão, envolvendo a produção e o compartilhamento sistematizado de saberes, e o impacto social que suas atividades promovem dentro e fora do ambiente de trabalho. Conclusão: evidências da percepção de docentes universitários da grande área da saúde sobre os seus próprios processos de saúde e adoecimento no trabalho apontam que as esferas pessoais, sociais e institucionais devem atuar conjuntamente para atender as complexas necessidades contemporâneas em saúde.

Palavras-chave: docente; universidade; promoção da saúde; satisfação no trabalho.

\begin{abstract}
Objective: to systematize studies that address the occupational determinants of health of university health professors. Methods: descriptive and analytical integrative review conducted in Brazilian and international electronic databases, based on studies published in Portuguese and English between January 2005 and March 2016. Results: application of the selection criteria resulted in the inclusion of twenty studies (three master dissertations, five doctoral theses and twelve articles). Predominantly, the studies pointed out that professors identify physical and psychological working conditions as negative aspects to health and, as health promoting aspects, the satisfaction with their profession - involving production and systematized sharing of knowledge - and the social impacts that their activities exert in and outside their workplace. Conclusion: evidences of health professors' perception on their own processes of health and illness at work indicate that personal, social and institutional spheres should work together to meet the contemporary complex health needs.
\end{abstract}

Keywords: professor; university, health promotion; work satisfaction. 


\section{Introdução}

Transformações contemporâneas apresentam novas dinâmicas e desafios a diversos fenômenos sociais ${ }^{1}$. A evolução tecnológica, a hiperconectividade, o avanço das ideologias neoliberais e da austeridade econômica no contexto produtivo, e os novos valores culturais, tais como imediatismo, individualismo, narcisismo, consumismo e hedonismo, dentre outros, afetam as relações e a saúde humanas ${ }^{2,3}$.

No contexto do trabalho, as mudanças citadas tanto proporcionam quanto demandam dos profissionais imediatismos resolutivos e atualizações constantes, afetando o ritmo e a capacidade de assimilação das tarefas. A vida no trabalho passa a existir numa temporalidade de aceleração permanente em busca de produtividade e competência e com o aumento dos dispositivos de controle que enfatizam ligações funcionais e pragmáticas dos trabalhadores no seu cotidiano ${ }^{4}$.

Tais aspectos vêm afetando drasticamente a saúde e a qualidade de vida de diversas categorias profissionais, dentre elas os docentes que atuam em Instituições de Ensino Superior (IES) ${ }^{5}$. A intensificação das exigências por geração de conhecimentos, formação profissional de qualidade e produção de novas tecnologias para o país se consolidam como tarefas adicionais a esses profissionais ${ }^{4,6,7}$, em especial por se referirem ao processo intelectual, investigativo e criativo, que não se encaixa na lógica produtivista $^{8}$. Alguns docentes, apesar de excelentes em sua área de atuação, passam a apresentar dificuldade em cumprir as atividades de ensino, pesquisa e extensão contempladas no "tripé universitário" e ainda se dedicar às atividades administrativas e financeiras que se acumulam na sua carga de responsabilidades ${ }^{9}$.

No entanto, o trabalho pode também representar fonte de prazer e realização pessoal ${ }^{10}$. Os obstáculos estimulam professores a criar estratégias para driblar as dificuldades cotidianas e as condições deficitárias de trabalho e a elaborar outras normas e regras que redefinem a técnica, encontrando modos de regulação que deem conta da variabilidade inerente à sua atividade. Assim emerge o trabalho real, que afirma a potência do vivo de reorganizar cotidianamente suas demandas ${ }^{11}$. O vínculo, um dos elementos básicos do processo de aproximação e interesse pela vida social, pode, ainda, ser um elemento importante para enfrentar as adversidades e suportar os níveis de estresse, angústia e de falta de sentido no trabalho ${ }^{8}$.

Ser professor é uma atividade profissional que exige clareza do papel do conhecimento nos processos de ensino e aprendizagem para formar profissionais capazes de transformar os conhecimentos aprendidos em atuações necessárias ao ambiente social em que estão inseridos, inclusive para o próprio docente ${ }^{12}$. Assim, o processo de saúde e adoecimento dos professores universitários deve ser entendido como um intrincado fenômeno sistêmico: cada vez que um dos componentes sofre uma alteração, esta repercute e atinge os demais fatores, desencadeando um processo para buscar um novo equilíbrio do sistema $a^{8,11,12}$.

Nesse panorama complexo nos interessa discutir o fenômeno da saúde em sua relação com o trabalho de docência em nível superior em professores que atuam em cursos da grande área da saúde. Isso porque o trabalho desses docentes que devem cuidar enquanto ensinam, além de atender às questões científicas, educacionais e de formação profissional, deve fomentar posturas e ambientes promotores de saúde, voltando-se às necessidades de saúde da população ${ }^{13}$.

Não obstante, essa exigência pode produzir uma incoerência: mesmo sendo autoridade científica na área, o profissional pode não conseguir agir ou promover a saúde de forma satisfatória ou em conformidade com as recomendações que ensina ${ }^{14,15}$. Tamanho desafio pode levar alguns docentes a vivenciarem a angústia de um paradoxo que Jung (1989) ${ }^{15}$ definiu como arquétipo "do curador adoecido", quando a vivência desses profissionais não se alinha com os preceitos defendidos e ensinados.

Nessa perspectiva, o presente artigo visa sistematizar estudos que abordam o tema da saúde dos professores universitários da grande área da saúde e os fatores ocupacionais condicionantes ou determinantes associados, e realizar uma reflexão sobre o tema. Tal reflexão pode fornecer elementos para compreender os papeis desses profissionais como agentes promotores da saúde (sua própria e da comunidade, inclusive a universitária), onde as práticas (pessoais e profissionais) sejam percebidas como importante elemento de formação pessoal e profissional, considerando também as condições objetivas e subjetivas das vivências do trabalho.

\section{Métodos}

Trata-se de uma revisão integrativa descritiva e analítica realizada a partir de artigos científicos, dissertações e teses que apresentaram como tema central a saúde de professores universitários brasileiros da área da saúde, publicados entre janeiro de 2005 e março de 2016. O método de revisão integrativa permite a combinação de estudos com diferentes abordagens metodológicas mantendo o rigor das revisões sistemáticas, e favorece a avaliação crítica e a síntese das evidências disponíveis do tema investigado ${ }^{16}$. 
A busca dos estudos foi realizada nas bases de dados PubMed, Medline, LILACS (Biblioteca Virtual em Saúde), SciELO, Google Scholar, Periódicos Capes e na Biblioteca Digital Brasileira de Teses e Dissertações do Instituto Brasileiro de Informação em Ciência e Tecnologia. Os descritores utilizados foram: "saúde, bem-estar, promoção de saúde, percepção de saúde, professores universitários, professores, e universidade" em português e "health, wellness, health promotion, health perception, professor, teacher, e university" em inglês. Além disso, as referências bibliográficas dos estudos encontrados também foram pesquisadas a fim de localizar mais trabalhos sobre o tema.

Foram selecionados os estudos que atenderam aos critérios de inclusão: ser trabalho científico (artigo, dissertação ou tese) disponível na íntegra online; ter amostra com professores universitários brasileiros de cursos que formam profissionais da grande área da saúde de acordo com a Resolução n ${ }^{\circ}$. 287/1998 do Conselho Nacional de Saúde (CNS) ${ }^{17}$; pesquisar sobre a situação de saúde no sentido amplo, contemplando mais de um indicador; e abordar os determinantes e condicionantes da saúde relacionados ao trabalho.

A Resolução CNS no 287, de 08 de outubro de 1998, relaciona as seguintes categorias profissionais de saúde de nível superior para fins de atuação do Conselho: Assistentes Sociais; Biólogos; Biomédicos; Profissionais de Educação Física; Enfermeiros; Farmacêuticos; Fisioterapeutas; Fonoaudiólogos; Médicos; Médicos Veterinários; Nutricionistas; Odontólogos; Psicólogos; e Terapeutas Ocupacionais ${ }^{17}$.

Optamos por incluir teses e dissertações não publicadas na forma de artigos para ampliar o número de estudos científicos consultados e, consequentemente, a abrangência das discussões entabuladas na presente revisão. Estudos exclusivamente descritivos sobre prevalência de doenças ou distúrbios (tais como doenças crônicas, síndrome da exaustão ou Burnout, distúrbios da voz, problemas e/ ou dores musculoesqueléticas) não foram incluídos, uma vez que a revisão busca esclarecimentos sobre os fatores condicionantes ou determinantes associados à saúde no trabalho, e não apenas descrever ou caracterizar a situação de saúde dos docentes. Em adição, foram excluídos estudos que contemplavam cursos superiores de outras áreas que não apresentaram os resultados estratificados para a área da saúde.

Os estudos selecionados foram agrupados por tipo de pesquisa (quantitativa, qualitativa ou mista) e em ordem crescente do ano de publicação e, quando do mesmo ano, em ordem alfabética considerando o sobrenome do primeiro autor. As características metodológicas, os principais objetivos, resultados e conclusões de cada estudo foram tabulados. Diante das informações sistematizadas, empreendemos uma análise crítica sobre a situação de saúde dos docentes universitários a partir dos condicionantes e determinantes relacionados ao trabalho. Nessa apreciação, partimos do entendimento que a saúde é um fenômeno complexo determinado por ampla rede de relações ${ }^{18}$, no qual vários fatores em sinergia determinarão o estado de saúde do indivíduo e da coletividade, consoante os referenciais teóricos da promoção da saúde ${ }^{19}$. Esse referencial teórico representa uma possibilidade concreta de ruptura do paradigma dominante, centrado na doença e no indivíduo, ao propor uma forma mais abrangente de conceber e intervir no campo da saúde ${ }^{20}$.

\section{Resultados}

Consultas às bases de dados retornaram 81 publicações sobre o tema. Após a aplicação dos critérios de inclusão, 24 estudos com professores de cursos superiores de outras áreas que não apresentaram resultados estratificados para a área da saúde; vinte estudos que abordaram um único critério de saúde e/ou não avaliaram fatores condicionantes ou determinantes da saúde associados ao trabalho, e dezessete relacionados exclusivamente à formação e desenvolvimento docente em saúde foram excluídos.

A presente revisão de literatura trabalhou com vinte estudos publicados nos últimos onze anos que contemplaram a saúde, seus determinantes e condicionantes, em professores universitários brasileiros que atuam na grande área da saúde. Foram utilizadas três teses, cinco dissertações e doze artigos científicos cujas características gerais podem ser vistas no Quadro 1.

As publicações foram agrupadas por tipo de pesquisa: oito estudos quantitativos ${ }^{1,21-27}$, nove estudos qualitativos ${ }^{6,8,12,28-33}$, e três estudos quanti-qualitativos $^{34-36}$. Há, ainda, informações sobre as características da amostra, tais como: número de participantes, cursos incluídos, tipo de vínculo com a instituição, prevalência por sexo, e o tipo (federal, estadual, municipal ou privada) e local (cidade e estado) da IES, além do desenho metodológico e os instrumentos utilizados.

Os objetivos dos trabalhos são variados, mas podem ser sintetizados como o estudo dos processos de saúde e adoecimento associados: às cargas psíquicas no trabalho; às condições físicas e organizacionais do trabalho; às relações interpessoais no trabalho; à satisfação no trabalho e capacidade para o trabalho; e aos sentidos de prazer e sofrimento no trabalho. 
Quadro 1 Características das publicações sobre saúde e fatores associados em professores universitários da área da saúde

\begin{tabular}{|c|c|c|c|c|}
\hline Ref\# & Tipo & Autor (ano) & Amostra & Desenho e Instrumentos \\
\hline 1 & Tese & Lemos (2005) & $\begin{array}{l}86 \text { professores } \\
\text { - Cursos } 1,2,3,4,5 \text { e } 12 . \\
\text {-60,5\% D.E. } \\
\text { - 64\% mulheres. } \\
\text { - Federal em Santa Maria, RS. }\end{array}$ & $\begin{array}{l}\text { Quantitativo, exploratório, com questionários de: } \\
\text {-Avaliação da Carga Psíquica do trabalho (Q-CP), } \\
\text {-Bem-Estar Psicológico. }\end{array}$ \\
\hline 21 & Artigo & \begin{tabular}{|l|} 
Marqueze e \\
Moreno (2009)
\end{tabular} & $\begin{array}{l}154 \text { professores } \\
\text { - Cursos da saúde N.I. } \\
\text { - 49,4\% mulheres } \\
\text { - Tipo e Local N.I. }\end{array}$ & $\begin{array}{l}\text { Quantitativo com questionários de: } \\
\text { - satisfação no trabalho do Occupational Stress } \\
\text { Indicator (OSI), } \\
\text { - Índice de Capacidade para o Trabalho. }\end{array}$ \\
\hline 22 & Artigo & $\begin{array}{l}\text { Fontana e } \\
\text { Pinheiro } \\
(2010)\end{array}$ & $\begin{array}{l}34 \text { professores } \\
\text { - Cursos } 2,5 \text { e } 8 . \\
\text { - } 41,1 \% \text { D.E. } \\
\text { - 62\% mulheres. } \\
\text { - Regional no noroeste do RS. } \\
\end{array}$ & $\begin{array}{l}\text { Quantitativo, epidemiológico, com questionários } \\
\text { de: } \\
\text { - condições de trabalho e saúde, incluindo } \\
\text { queixas de morbidade e exposição a riscos } \\
\text { ocupacionais. }\end{array}$ \\
\hline 23 & Artigo & $\begin{array}{l}\text { Servilha e } \\
\text { Arbach (2011) }\end{array}$ & $\begin{array}{l}85 \text { professores } \\
\text { - Cursos da saúde N.I. } \\
\text { - 33,3\% D.E. } \\
\text { - 71,4\% mulheres. } \\
\text { - Tipo e local N.I. } \\
\end{array}$ & $\begin{array}{l}\text { Quantitativo, epidemiológico, com questionários } \\
\text { de: } \\
\text { - com informações pessoais, profissionais e de } \\
\text { saúde. } \\
\text { - produção vocal do professor (CPV-P). }\end{array}$ \\
\hline 24 & Dissertação & Ferreira (2011) & $\begin{array}{l}108 \text { professores } \\
\text { - Cursos 1, 2, 4, } 5 \text { e } 7 . \\
\text {-65,7\% D.E. } \\
\text { - 68,5\% mulheres. } \\
\text { - Pública em Goiânia, GO. } \\
\end{array}$ & $\begin{array}{l}\text { Quantitativo, exploratório com questionários de: } \\
\text { - Qualidade de vida em relação à saúde (Medical } \\
\text { Outcome Study); } \\
\text { - Satisfação no Trabalho (S20/23). }\end{array}$ \\
\hline 25 & Dissertação & Santos (2013) & $\begin{array}{l}175 \text { professores } \\
\text { - Cursos todos menos o } 9 . \\
\text { - 92\% D.E. } \\
\text {-60,6\% mulheres. } \\
\text { - Federal em Recife, PE. }\end{array}$ & $\begin{array}{l}\text { Quantitativo, exploratório, com questionários de: } \\
\text { - Atividade docente, ambiente de trabalho e } \\
\text { saúde, } \\
\text { - Características psicossociais do trabalho (JSS), } \\
\text { - Emoções (SRQ-20), } \\
\text { - Apoio social geral (MOS-SSS), } \\
\text { - Escala de Bem-Estar no Trabalho (EBET). }\end{array}$ \\
\hline 26 & Dissertação & Priess (2011) & $\begin{array}{l}88 \text { professores } \\
\text { - Cursos 2, 5, 6, 7, 8, } 10 \text { e } 11 . \\
\text { - 25\% D.E. } \\
\text { - 59\% mulheres. } \\
\text { - Privada em Foz do Iguaçu, PR. }\end{array}$ & $\begin{array}{l}\text { Quantitativo, exploratório com questionários de: } \\
\text { - Avaliação da Qualidade de Vida e Saúde (QVS- } \\
\text { 80) nos domínios: saúde, atividade física, } \\
\text { ambiente ocupacional e } \\
\text { - Percepção da qualidade de vida. }\end{array}$ \\
\hline 27 & Artigo & $\begin{array}{l}\text { Ferreira et al. } \\
(2015)\end{array}$ & $\begin{array}{l}175 \text { professores } \\
\text { - Cursos 1, 2, 3, 4, 5, 7, } 8 \text { e } 12 . \\
\text { - 31,8 D.E. } \\
\text { - 53,1\% mulheres. } \\
\text { - Privada de Minas Gerais, MG. }\end{array}$ & $\begin{array}{l}\text { Quantitativo, exploratório com questionários com: } \\
\text { - Avaliação de qualidade de vida (WHOQOL-bref); } \\
\text { - dados demográficos, comportamentos e } \\
\text { história ocupacional; } \\
\text { - Sobre Saúde Geral (QSG-12); } \\
\text { - escala de esforço, recompensa, e } \\
\text { comprometimento no trabalho; } \\
\text { - Questionário Internacional de Atividades } \\
\text { Físicas (IPAQ) }\end{array}$ \\
\hline 6 & Artigo & $\begin{array}{l}\text { Coutinho et al. } \\
(2011)\end{array}$ & $\begin{array}{l}8 \text { professores } \\
\text { - Cursos } 6 \text { e } 11 . \\
\text { - 37,5\% D.E. } \\
\text { - 75\% mulheres. } \\
\text { - Pública e privada em local NI. }\end{array}$ & $\begin{array}{l}\text { Qualitativo, exploratório, com entrevistas sobre: } \\
\text { - Trajetória profissional; condições, carga, } \\
\text { ambiente e relações e expectativas no trabalho; } \\
\text { pressões e estratégias de resistência. }\end{array}$ \\
\hline 8 & Artigo & $\begin{array}{l}\text { Garcia, } \\
\text { Oliveira e } \\
\text { Mauro (2008) }\end{array}$ & $\begin{array}{l}25 \text { professores } \\
\text { - Cursos } 1,2,4,6,7,8,12 \text { e } 13 . \\
\text { - } 76 \% \text { mulheres. } \\
\text { - Tipo N.I. no ES. }\end{array}$ & $\begin{array}{l}\text { Qualitativo, exploratório, com entrevistas sobre: } \\
\text { - Fatores que afetam a qualidade de vida; } \\
\text { - repercussão do trabalho nas demais relações } \\
\text { sociais e condições e organização do trabalho. }\end{array}$ \\
\hline
\end{tabular}

(Continua) 
Quadro 1 Continuação...

\begin{tabular}{|c|c|c|c|c|}
\hline Ref\# & Tipo & Autor (ano) & Amostra & Desenho e Instrumentos \\
\hline 12 & Dissertação & Ulrich (2005) & $\begin{array}{l}11 \text { professores } \\
\text { - Curso } 8 . \\
\text { - 45,5\% D.E. } \\
\text { - 36,4\% mulheres. } \\
\text { - Municipal no interior RS. }\end{array}$ & $\begin{array}{l}\text { Qualitativo, exploratório, com entrevistas sobre: } \\
\text { - Percepção do trabalho, relações interpessoais, } \\
\text { relações hierárquicas, e trabalho e saúde. }\end{array}$ \\
\hline 28 & Artigo & $\begin{array}{l}\text { Silvério et al. } \\
(2009)\end{array}$ & $\begin{array}{l}27 \text { professores } \\
\text { - Cursos 1, 2, 3, 4, } 5 \text { e } 6 . \\
\text { - Sexo N.I. } \\
\text { - Federal em Santa Catarina, SC. }\end{array}$ & $\begin{array}{l}\text { Qualitativo, exploratório, com entrevistas sobre: } \\
\text { - Fatores ambientais que influenciam os } \\
\text { processos de ensino-aprendizagem e a } \\
\text { qualidade de vida e saúde. }\end{array}$ \\
\hline 29 & Artigo & $\begin{array}{l}\text { Oliveira et al. } \\
(2012)\end{array}$ & $\begin{array}{l}19 \text { professores } \\
\text { - Cursos N.I. } \\
\text { - 100\% mulheres. } \\
\text { - Pública e Privada em Vitória, ES. }\end{array}$ & $\begin{array}{l}\text { Qualitativo, exploratório com entrevistas sobre: } \\
\text { - Dedicação à família, lazer e trabalho. }\end{array}$ \\
\hline 30 & Dissertação & Rohde (2012) & $\begin{array}{l}10 \text { professores } \\
\text { - Curso } 6 . \\
\text { - } 40 \% \text { mulheres. } \\
\text { - Federal na Região Sul, RS. }\end{array}$ & $\begin{array}{l}\text { Qualitativo, exploratório, com entrevistas sobre } \\
\text { aspectos: } \\
\text { - Físico, psicológico, relações sociais e ambiente. }\end{array}$ \\
\hline 31 & Artigo & $\begin{array}{l}\text { Lago, Cunha e } \\
\text { Borges (2015) }\end{array}$ & $\begin{array}{l}6 \text { professores } \\
\text { - Cursos } 1,2,7,8 \text { e } 9 . \\
\text { - 66,5\% mulheres. } \\
\text { - Federal na Região Norte, AM. }\end{array}$ & $\begin{array}{l}\text { Qualitativo, exploratório-descritivo, com } \\
\text { entrevistas: } \\
\text { - Expectativas, dificuldades e facilidades no } \\
\text { trabalho; } \\
\text { - mudanças na qualidade de vida e saúde; } \\
\text { - inter-relação com discentes e profissionais; } \\
\text { - estratégias de ensino-aprendizagem utilizadas. }\end{array}$ \\
\hline 32 & Artigo & $\begin{array}{l}\text { Gonçalves e } \\
\text { Pires (2015) }\end{array}$ & $\begin{array}{l}25 \text { professores } \\
\text { - Curso } 1,2 \text { e } 4 . \\
-76 \% \text { mulheres. } \\
\text { - Federal da Região Norte, PA. }\end{array}$ & $\begin{array}{l}\text { Qualitativo, exploratório-descritivo, com } \\
\text { entrevistas sobre: } \\
\text { - Situações geradoras de prazer no trabalho; } \\
\text { - situações geradoras de sofrimento no trabalho. }\end{array}$ \\
\hline 33 & Artigo & $\begin{array}{l}\text { Santos et al. } \\
(2016)\end{array}$ & $\begin{array}{l}21 \text { professores } \\
\text { - Curso } 1 \text { e } 2 . \\
\text { - 52,4\% D.E. } \\
\text { - 38,1\% mulheres. } \\
\text { - Federal do Rio Grande do Norte, } \\
\text { RN. } \\
\end{array}$ & $\begin{array}{l}\text { Qualitativo, exploratório-descritivo, com } \\
\text { entrevistas sobre: } \\
\text { - Atividades em uma semana normal de trabalho; } \\
\text { - aspectos desgastante em sala de aulas ou estágio; } \\
\text { - relacionamento interpessoal na docência; } \\
\text { - atividades externas ao trabalho. }\end{array}$ \\
\hline 34 & Artigo & $\begin{array}{l}\text { Lima e Filho } \\
(2009)\end{array}$ & $\begin{array}{l}189 \text { professores } \\
\text { - Cursos 1, 2, 4, 5, } 6 \text { e } 11 . \\
\text { - 74,9\% D.E. } \\
\text { 38,5\% mulheres. } \\
\text { - Federal em Campo Grande, MS. }\end{array}$ & $\begin{array}{l}\text { Quanti-qualitativo, exploratório com } \\
\text { questionários de: } \\
\text { - Condições físicas e atividades do trabalho; } \\
\text { e entrevistas sobre: } \\
\text { - problemas e doenças associados ao trabalho, } \\
\text { - relação com os pares e expectativas com a } \\
\text { carreira. }\end{array}$ \\
\hline 35 & Tese & $\begin{array}{l}\text { Dallacosta } \\
(2014)\end{array}$ & $\begin{array}{l}139 \text { professores } \\
\text { - Cursos } 1,2,3,4,6,8 \text { e } 11 . \\
\text { - } 74,9 \% \text { D.E. } \\
\text { - 51,1\% mulheres. } \\
\text { - } 2 \text { IES privadas em Santa Catarina, } \\
\text { SC. }\end{array}$ & $\begin{array}{l}\text { Quanti-qualitativo, exploratório com } \\
\text { questionários de: } \\
\text { - Occupational Stress Indicator (OSI), } \\
\text { - Inventário de Burnout de Maslach (MBI). } \\
\text { e entrevistas sobre: } \\
\text { - dados sociodemográficos e situação profissional. }\end{array}$ \\
\hline 36 & Tese & Treviso (2015) & $\begin{array}{l}85 \text { professores } \\
\text { - Cursos 2, 3, 5, 6, 7, 8, 10, 12, } 13 \\
\text { e SS. } \\
\text { - 27\% D.E. } \\
\text { - 71\% mulheres. } \\
\text { - Privada no Rio Grande do Sul, RS. }\end{array}$ & $\begin{array}{l}\text { Quanti-qualitativo, exploratório com } \\
\text { questionários de: } \\
\text { - Três categorias: Formação, Atuação, Satisfação; } \\
\text { e Entrevistas sobre: } \\
\text { - características demográficas da população; } \\
\text { - formação, atuação e satisfação no trabalho. }\end{array}$ \\
\hline
\end{tabular}

IES: Instituição de Ensino Superior; N.I.: não informado; D.E.: dedicação exclusiva; DCS: Departamento de Ciências da Saúde; Cursos: 1-Medicina; 2-Enfermagem; 3-Fisioterapia; 4-Odontologia; 5-Farmácia; 6-Psicologia; 7-Nutrição; 8-Educação Física; 9-Saúde Coletiva; 10-Biomedicina; 11-Ciências Biológicas; 12-Fonoaudiologia; 13-Terapia Ocupacional; SS: Serviço social; Estados: RS, Rio Grande do Sul; GO, Goiás; PE, Pernambuco; ES, Espírito Santo; MS, Mato Grosso do Sul; PR, Paraná. 
Todos os oito estudos quantitativos ${ }^{1,21-27}$ foram transversais, descritivos e utilizaram questionários variados para obter informações sobre características sócio-demográficas e laborais dos docentes. Desses, dois estudos se denominaram epidemiológicos ${ }^{22,23}$, mas a amostra investigada foi um pequeno grupo não representativo de professores. Dos nove estudos qualitativos todos aplicaram entrevistas ${ }^{6,8,12,28-33}$, oito de forma individual e um em grupo focal, e sete utilizaram análise de conteúdo para identificação de categorias. Os três estudos mistos, com abordagens qualitativa e quantitativa, usaram questionários e entrevistas ${ }^{34-36}$.

Dos vinte estudos, catorze ${ }^{1,12, ~ 21-22, ~ 24-27, ~ 30-32, ~ 34-36 ~ a b o r-~}$ daram o tema sob a perspectiva dos sujeitos em estudo, e registraram, analisaram e relacionaram dados e informações de saúde procurando descobrir a frequência com que um fenômeno ocorre, sua natureza e características, e sua relação e conexão com outros fenômenos, em especial o exercício docente no ensino superior de graduação na área da saúde. Os demais seis ${ }^{6,8,23,28,29,33}$ estudos que não utilizaram frequência descritiva relataram diferentes fatores e aspectos relacionados às instituições, interação com gestores e colegas de trabalho, bem como as condições de trabalho e os sentidos de prazer e sofrimento no trabalho.

Quatro estudos foram desenvolvidos somente em instituições privadas ${ }^{26,27,35,36}$; onze em instituições públicas (nove federais ${ }^{1,24,25,28,30-34}$, uma municipal ${ }^{12}$ e uma regional ${ }^{22}$ ); dois estudos comparam IES públicas e privadas ${ }^{6,29}$, onde cabe destacar a maior instabilidade psicológica, de horários e do próprio emprego; e em três estudos não foi possível identificar o tipo e/ou o local da instituição $0^{8,21,23}$. Apenas seis estudos apresentam mais de $50 \%$ da amostra sendo dedicação exclusiva na IES $^{1,24,25,33-35}$ e dezessete estudos apresentaram predominância do sexo feminino no grupo estudado.

Oito estudos foram realizados na região Sul (cinco no Rio Grande do Sul 1,12,22,30,36, dois em Santa Catarina $^{28,35}$ e um no Paraná ${ }^{26}$ ), três na região Sudeste (dois no Espírito Santo ${ }^{8,29}$ e um em Minas Gerais ${ }^{27}$ ), dois na região Centro-Oeste (Goiás ${ }^{24}$ e Mato Grosso do $\mathrm{Sul}^{34}$ ), dois na região Nordeste (Pernambuco ${ }^{25}$ e Rio Grande do Norte ${ }^{33}$ ) e dois na região Norte (Manaus ${ }^{31}$ e Pará ${ }^{32}$ ); em três estudos não foi possível identificar a região ou o estado ${ }^{6,21,23}$. A maior parte dos autores dos trabalhos selecionados estava filiada à grande área da saúde, especificamente enfermagem, medicina, odontologia, farmácia, psicologia e educação física.

A despeito de todos os estudos abordarem a saúde e o adoecimento em relação aos processos de trabalho, houve ampla variação nas palavras-chave utilizadas. As que apresentaram maior repetição nos estudos foram: saúde, docente ou professor, ensino ou educação ou magistério, e nível superior ou universitário.

Os principais resultados e conclusões das publicações sobre a saúde dos professores universitários da área de saúde e aspectos relacionados ao trabalho foram descritos no Quadro 2. Os aspectos negativos à saúde apresentados pelos estudos permitem ampliar o grau de compreensão acerca dos riscos e evidências de processos de adoecimento, em especial nas dimensões físicas e psicológicas relacionados às condições de trabalho no ambiente universitário. Fatores positivos à saúde estão relacionados à satisfação profissional decorrentes da produção de conhecimento e do impacto social que suas atividades de trabalho promovem e podem contribuir com a criação, difusão e implementação de estratégias promotoras de saúde no ambiente de trabalho ou fora dele.

\section{Discussão}

Ao empreender a revisão de literatura, nos deparamos com poucas publicações nos últimos onze anos que se dedicaram a compreender os determinantes e condicionantes da saúde relacionados ao trabalho de professores de IES que atuam em cursos da saúde. Em geral os estudos foram realizados em uma única instituição ou no máximo comparam duas instituições da mesma cidade/estado, não apresentando um panorama nacional sobre o tema. A revisão aqui exposta apresenta os principais resultados e conclusões de estudos produzidos nas cinco regiões brasileiras e promove uma síntese da temática ao discutir algumas convergências para fortalecimento de consenso e divergências entre os estudos, comparando também com outros dados nacionais.

Informações sobre as IES no país ${ }^{37-40}$ indicam maior prevalência (66\%) de IES estabelecidas nas regiões Sul e Sudeste, de forma similar à prevalência de $60 \%$ dos trabalhos contemplados nessa revisão publicados nessas regiões. Não obstante, quando analisados por categoria administrativa, os estudos produzidos sobre as IES não representam a realidade nacional, sendo majoritariamente desenvolvidos em IES públicas; principalmente federais (45\%). Das 2.391 IES reconhecidas no território brasileiro em 2013, menos de 15\% eram públicas (4\% federais, $5 \%$ estaduais e $3 \%$ municipais) $)^{39,41}$.

Quando analisamos dados quantitativos nacionais dos cursos da saúde e bem-estar social - que contemplam os cursos de terapia e reabilitação; enfermagem; farmácia; saúde (cursos gerais); odontologia; medicina; tecnologias de diagnósticos e tratamento médico; e serviços sociais e orientação ${ }^{42,43}$, identificamos que há uma prevalência maior de cursos da área da saúde sendo oferecidos em IES públicas (22\%); e que os cursos listados diferem das categorias de profissionais de saúde de nível superior da Resolução CNS n ${ }^{\circ}$ 287/1998 ${ }^{17}$, faltando nos estudos os cursos de ciências biológicas; biomedicina; educação física; fisioterapia; fonoaudiologia; medicina veterinária; nutrição; psicologia; e terapia ocupacional. 
Quadro 2 Principais objetivos, resultados e conclusões das publicações sobre a saúde dos professores universitários da área de saúde

\begin{tabular}{|c|c|c|c|}
\hline Ref\# & Autor (ano) & Objetivos & Principais resultados e conclusões \\
\hline 1 & $\begin{array}{l}\text { Lemos } \\
(2005)\end{array}$ & $\begin{array}{l}\text { Caracterizar as cargas } \\
\text { psíquicas no trabalho } \\
\text { e sua influência nos } \\
\text { processos de saúde. }\end{array}$ & $\begin{array}{l}\text { As dimensões físicas e psicológicas da carga de trabalho apresentam relação com a } \\
\text { percepção das condições de trabalho e dos riscos de adoecimento. } \\
\text { As condições de trabalho e o estado de bem-estar psicológico do professor influenciam } \\
\text { significativamente os processos de saúde e adoecimento. } \\
\text { A dor e desconforto estão intimamente relacionados à precariedade das condições de } \\
\text { trabalho. O tempo de docência e o número de disciplinas lecionadas no semestre não } \\
\text { parecem afetar esses aspectos. } \\
\text { A precarização das relações de trabalho apresenta repercussões na saúde dos professores } \\
\text { e na qualidade do ensino superior público. }\end{array}$ \\
\hline 21 & $\begin{array}{l}\text { Marqueze } \\
\text { e Moreno } \\
(2009)\end{array}$ & $\begin{array}{l}\text { Verificar a relação } \\
\text { entre satisfação no } \\
\text { trabalho e capacidade } \\
\text { para o trabalho. }\end{array}$ & $\begin{array}{l}\text { Aspectos de insatisfação com o trabalho (volume de trabalho, grau de instabilidade no } \\
\text { emprego e grau que a instituição absorve suas potencialidades) estão relacionados à } \\
\text { gestão da universidade. } \\
\text { Aspectos de satisfação com o trabalho estão relacionados ao conteúdo e ambiente do } \\
\text { trabalho, relacionamento interpessoal e motivação. } \\
\text { A diminuição da capacidade para o trabalho pode ter relação com a atuação paralela dos } \\
\text { docentes em serviços de saúde, o que exige grande envolvimento cognitivo. }\end{array}$ \\
\hline 22 & $\begin{array}{l}\text { Fontana e } \\
\text { Pinheiro } \\
(2010)\end{array}$ & $\begin{array}{l}\text { Investigar as } \\
\text { condições de saúde } \\
\text { autorreferidas } \\
\text { e a interface } \\
\text { com a ocupação } \\
\text { profissional. }\end{array}$ & $\begin{array}{l}\text { A maior queixa dos professores foram às dores, associadas aos longos períodos em pé e } \\
\text { às tensões. } \\
\text { Interfaces negativas decorrem da situação dos ambientes de prática externos, } \\
\text { considerados deficitários de conforto e praticidade (e.g.: faltam salas, mobiliários e } \\
\text { informatização adequados). } \\
\text { Interfaces positivas se referem à infraestrutura apropriada, laboratórios para a prática } \\
\text { do ensino, organização da universidade, boas relações interpessoais e salário acima da } \\
\text { média. } \\
\text { A gestão que priorize promover a saúde deve valorizar o docente, diminuir a carga de } \\
\text { trabalho e oferecer melhores condições, recursos e fomentos para a concretização digna } \\
\text { do ensino, pesquisa e extensão. }\end{array}$ \\
\hline 23 & $\begin{array}{l}\text { Servilha } \\
\text { e Arbach } \\
(2011)\end{array}$ & $\begin{array}{l}\text { Investigar a relação } \\
\text { entre condições } \\
\text { organizacionais do } \\
\text { trabalho e queixas } \\
\text { de saúde. }\end{array}$ & $\begin{array}{l}\text { Condições organizacionais negativas: ritmo de trabalho estressante, levar trabalho para } \\
\text { casa, interferência de fatores do ambiente de trabalho na vida pessoal, esforço físico ao } \\
\text { carregar peso com frequência, supervisão constante e trabalho repetitivo. } \\
\text { Condições organizacionais positivas: condições de higiene, mobiliário, tempo para } \\
\text { desenvolver as atividades, espaço para movimentação, tamanho das salas adequado, } \\
\text { ambiente de trabalho calmo, e facilidade para se ausentar da sala de aula. } \\
\text { Queixas de saúde mais frequentes foram problemas respiratórios, osteoarticulares, } \\
\text { gastrintestinais e vocais. } \\
\text { IES devem prezar pelo aperfeiçoamento progressivo e sistemático das condições } \\
\text { de trabalho, favorecendo sua missão de produção de conhecimentos, valores e } \\
\text { desenvolvimento humano. }\end{array}$ \\
\hline 24 & $\begin{array}{l}\text { Ferreira } \\
\text { (2011) }\end{array}$ & $\begin{array}{l}\text { Analisar a satisfação } \\
\text { no trabalho e seu } \\
\text { reflexo na qualidade } \\
\text { de vida. }\end{array}$ & $\begin{array}{l}\text { A insatisfação dos docentes foi maior nos itens de relação hierárquica e ambiente físico. } \\
\text { A satisfação com o trabalho refere-se à realização, onde faz coisas que gosta e se destaca. } \\
\text { Esse aspecto afeta positivamente a qualidade de vida. } \\
\text { Gestores e docentes devem conjuntamente desenvolver uma gestão universitária } \\
\text { inovadora, que minimize as limitações físicas do ambiente laboral e favoreça o diálogo e a } \\
\text { participação nas decisões coletivas. }\end{array}$ \\
\hline 25 & $\begin{array}{l}\text { Santos } \\
\text { (2013) }\end{array}$ & $\begin{array}{l}\text { Conhecer a associação } \\
\text { entre Bem-Estar } \\
\text { no Trabalho e as } \\
\text { condições físicas e } \\
\text { organizacionais do } \\
\text { trabalho. }\end{array}$ & $\begin{array}{l}\text { As condições físicas e organizacionais do ambiente de trabalho não constituem um fator } \\
\text { significativo para determinar o bem-estar dos docentes. } \\
\text { É possível que a instituição investigada ofereça condições mínimas de trabalho aos } \\
\text { professores, o que diminui a percepção do impacto negativo desse aspecto sobre o } \\
\text { bem-estar. }\end{array}$ \\
\hline 26 & $\begin{array}{l}\text { Priess } \\
\text { (2011) }\end{array}$ & $\begin{array}{l}\text { Analisar aspectos do } \\
\text { estilo e da qualidade } \\
\text { de vida e comparar } \\
\text { com a prática regular } \\
\text { de atividades físicas. }\end{array}$ & $\begin{array}{l}\text { No geral os professores relatam um nível de satisfação excelente com os ambientes laborais. } \\
\text { Os domínios ambiente ocupacional e saúde representaram os menores impactos na } \\
\text { qualidade de vida. } \\
\text { O domínio da atividade física representou o maior impacto na qualidade de vida. Há } \\
\text { elevada prevalência de docentes sedentários, inclusive na educação física, estando mais } \\
\text { propensos a doenças crônicas. }\end{array}$ \\
\hline
\end{tabular}


Quadro 2 Continuação...

\begin{tabular}{|c|c|c|c|}
\hline Ref\# & Autor (ano) & Objetivos & Principais resultados e conclusões \\
\hline 27 & \begin{tabular}{|l|} 
Ferreira \\
et al. (2015)
\end{tabular} & \begin{tabular}{|l|} 
Avaliar a associação \\
entre estressores no \\
trabalho e transtornos \\
mentais.
\end{tabular} & $\begin{array}{l}\text { A prevalência de transtornos mentais foi maior entre professores com maior tempo de } \\
\text { trabalho e menor naqueles com maior qualidade de vida no domínio físico. }\end{array}$ \\
\hline 6 & $\begin{array}{l}\text { Coutinho } \\
\text { et al. }(2011)\end{array}$ & $\begin{array}{l}\text { Compreender os } \\
\text { sentidos de prazer } \\
\text { e sofrimento no } \\
\text { trabalho. }\end{array}$ & $\begin{array}{l}\text { Vivencias de sofrimento foram associadas ao desgaste provocado pela grande carga de } \\
\text { trabalho, o medo e a insegurança de contratos precários, e as relações hierarquizadas e } \\
\text { competitivas no contexto organizacional que minam as relações solidárias. } \\
\text { Vivências positivas envolvem relações de troca e amizade com colegas e alunos e } \\
\text { o reconhecimento do trabalho. A atividade docente como prática criativa propicia } \\
\text { reconhecimento e identidade aos entrevistados. }\end{array}$ \\
\hline 8 & \begin{tabular}{|l|} 
Garcia, \\
Oliveira, \\
Mauro et al. \\
$(2008)$
\end{tabular} & $\begin{array}{l}\text { Analisar as condições } \\
\text { de trabalho no âmbito } \\
\text { das transformações } \\
\text { econômicas, sociais } \\
\text { e culturais. }\end{array}$ & $\begin{array}{l}\text { Condições de trabalho negativas foram a situação financeira e a estrutura física da } \\
\text { instituição, as pressões psicológicas e a falta de espaços para a troca de ideias. } \\
\text { A dedicação à atividade docente dificulta sua integração na vida para além dos espaços } \\
\text { da faculdade. } \\
\text { O docente se encontra só, sem apoio social necessário, com pouco apoio institucional } \\
\text { e mergulhado em demandas e exigências, que intensificam um sentido negativo do } \\
\text { processo de trabalho. } \\
\text { Aspectos positivos que melhoram a qualidade de vida foram a satisfação relacionada à } \\
\text { produção de conhecimento sistematizado e o impacto social que suas atividades promovem. } \\
\text { O próprio docente é capaz de desenvolver estratégias (internas e externas) de melhoria na } \\
\text { qualidade de vida resgatando a função social de prazer e solidariedade nas relações de trabalho. }\end{array}$ \\
\hline 12 & $\begin{array}{l}\text { Ulrich } \\
(2005)\end{array}$ & $\begin{array}{l}\text { Verificar se professores } \\
\text { compreendem as } \\
\text { relações interpessoais } \\
\text { como determinantes } \\
\text { de desgaste físico e } \\
\text { psicológico (estresse). }\end{array}$ & $\begin{array}{l}\text { Em geral professores indicaram mais aspectos desagradáveis do que agradáveis no } \\
\text { trabalho e em situações específicas de relação pessoal. Essa percepção pode gerar um } \\
\text { desgaste físico e psicológico dos professores. } \\
\text { A falta de colaboração entre os docentes e o não envolvimento dos professores em atividades } \\
\text { fora de sala de aula contribui para que o ensino seja realizado de forma fragmentada. } \\
\text { Situações agradáveis relatadas se referem ao relacionamento interpessoal, notadamente a } \\
\text { "colaboração" e, na categoria "ambiente de trabalho", há o "crescimento da organização". }\end{array}$ \\
\hline 28 & $\begin{array}{l}\text { Silvério } \\
\text { et al. (2009) }\end{array}$ & $\begin{array}{l}\text { Conhecer a } \\
\text { repercussão } \\
\text { do processo de } \\
\text { ensino-aprendizagem } \\
\text { na qualidade de vida e } \\
\text { saúde de docentes. }\end{array}$ & $\begin{array}{l}\text { As interações sociais nos diversos contextos do processo de ensino-aprendizagem e nas } \\
\text { demais relações do cotidiano universitário interferem significativamente na qualidade de } \\
\text { vida e saúde dos docentes. } \\
\text { O excesso de horas de trabalho, a falta de tempo e os conflitos e dilemas éticos que } \\
\text { envolvem o professor foram fatores limitantes da qualidade de vida dos docentes. } \\
\text { Interações entre professor, aluno e população (incluindo demonstrações de respeito } \\
\text { e reconhecimento do trabalho, troca de conhecimentos e afetividades) promovem } \\
\text { realização pessoal e profissional. }\end{array}$ \\
\hline 29 & $\begin{array}{l}\text { Oliveira } \\
\text { et al. }(2012)\end{array}$ & $\begin{array}{l}\text { Avaliar as condições } \\
\text { de trabalho sobre a } \\
\text { saúde e a qualidade } \\
\text { de vida percebida. }\end{array}$ & $\begin{array}{l}\text { Excesso de trabalho e alterações significativas em sua organização provocam falta de tempo } \\
\text { para lazer, comprometimento da interação social e familiar, aumento de distúrbios do sono, } \\
\text { favorecimento de doenças psíquicas e redução da saúde e da qualidade de vida. } \\
\text { Tarefas extraclasse, extensa jornada de trabalho, curto prazo para cumprir tarefas, } \\
\text { múltiplos empregos e elevada carga horária em sala, além de grau elevado de relação com } \\
\text { o público, têm resultado em Esgotamento Profissional. }\end{array}$ \\
\hline 30 & $\begin{array}{l}\text { Rohde } \\
(2012)\end{array}$ & $\begin{array}{l}\text { Compreender a } \\
\text { percepção sobre } \\
\text { qualidade de vida no } \\
\text { trabalho. }\end{array}$ & $\begin{array}{l}\text { Angústia em relação ao local não propício ao desenvolvimento da docência, afetando a } \\
\text { qualidade de vida. } \\
\text { Aspectos positivos indicam dedicação, comprometimento, respeito e admiração } \\
\text { pela Instituição. } \\
\text { Há a necessidade de conscientização dos professores e da instituição sobre o cuidado } \\
\text { com a saúde e sua relação com o ambiente de trabalho. }\end{array}$ \\
\hline 31 & $\begin{array}{l}\text { Lago, Cunha } \\
\text { e Borges } \\
(2015)\end{array}$ & $\begin{array}{l}\text { Conhecer a percepção } \\
\text { da experiência do } \\
\text { trabalho docente em } \\
\text { relação à saúde. }\end{array}$ & $\begin{array}{l}\text { Aspectos negativos incluem dificuldades no relacionamento com alunos, decorrentes } \\
\text { do momento de vida conflituoso (autonomia conquistada vs. as novas exigências com o } \\
\text { ingresso na faculdade). } \\
\text { Aspectos positivos incluem autonomia criativa para exercer a docência, oportunidade de } \\
\text { formação continuada, estabilidade empregatícia, e possibilidade de relações com alunos } \\
\text { e professores. } \\
\text { A maior parte dos docentes sente sua saúde vulnerável e desgastada, principalmente } \\
\text { em aspectos psicoemocionais, o que influencia as relações dentro e fora do trabalho e a } \\
\text { qualidade de vida. }\end{array}$ \\
\hline
\end{tabular}


Quadro 2 Continuação...

\begin{tabular}{|c|c|c|c|}
\hline Ref\# & Autor (ano) & Objetivos & Principais resultados e conclusões \\
\hline 32 & $\begin{array}{l}\text { Gonçalves } \\
\text { e Pires } \\
(2015)\end{array}$ & $\begin{array}{l}\text { Analisar as situações } \\
\text { geradoras de prazer } \\
\text { e sofrimento no } \\
\text { trabalho de docentes } \\
\text { da saúde. }\end{array}$ & $\begin{array}{l}\text { O sofrimento provém da insuficiência da remuneração, da precariedade da infraestrutura } \\
\text { e das dificuldades nas relações interpessoais. } \\
\text { Os resultados mostraram que o prazer advém do gostar da docência, do reconhecimento } \\
\text { e dos bons resultados do trabalho realizado. } \\
\text { Conclui que as situações geradoras de prazer e de sofrimento se expressam } \\
\text { dialeticamente no processo de trabalho dos docentes universitários da saúde e que gostar } \\
\text { do que faz promove satisfação, ainda que as condições de trabalho causem sofrimento. }\end{array}$ \\
\hline 33 & $\begin{array}{l}\text { Santos et al. } \\
(2016)\end{array}$ & $\begin{array}{l}\text { Conhecer a } \\
\text { percepção quanto } \\
\text { aos estressores } \\
\text { no ambiente } \\
\text { ocupacional. }\end{array}$ & $\begin{array}{l}\text { O “estresse no cotidiano docente” revela o quanto os professores são afetados pelo } \\
\text { estresse; com diferenças nas vivências dos docentes de Enfermagem e Medicina. } \\
\text { O “corpo dos docentes” revela reflexos físicos e psicológicos do estresse, com } \\
\text { repercussão em nível individual e organizacional. } \\
\text { Aspectos relacionados à sala de aula e ao sistema de saúde repercutem na forma de } \\
\text { desgaste físico e emocional dos docentes, embora alguns momentos em sala sejam } \\
\text { percebidos como um ato de realização profissional. } \\
\text { É importante cuidar da saúde física e mental dos docentes. }\end{array}$ \\
\hline 34 & $\begin{array}{l}\text { Lima e Filho } \\
(2009)\end{array}$ & $\begin{array}{l}\text { Verificar relações } \\
\text { entre o processo e as } \\
\text { condições de trabalho } \\
\text { e o adoecimento } \\
\text { físico e mental. }\end{array}$ & $\begin{array}{l}\text { A precarização do trabalho docente decorre de insuficiência de pessoal, sobrecarga de } \\
\text { trabalho, falta de materiais, equipamentos, apoio administrativo e ambiente inadequado. } \\
\text { O ambiente do trabalho (incluindo ruídos, ventilação umidade, temperatura, arranjo físico } \\
\text { e segurança) é considerado fator de risco para danos físicos ou mentais. } \\
\text { Os processos de trabalho interferem na saúde de professores, sejam relacionados à } \\
\text { natureza das funções que exercem ou vinculados ao contexto institucional e social onde } \\
\text { estes são exercidos. }\end{array}$ \\
\hline 35 & $\begin{array}{l}\text { Dallacosta } \\
(2014)\end{array}$ & $\begin{array}{l}\text { Avaliar a satisfação } \\
\text { no trabalho e o } \\
\text { esgotamento } \\
\text { profissional. }\end{array}$ & $\begin{array}{l}\text { Os professores apresentaram altos índices de exaustão emocional, despersonalização } \\
\text { e pouca realização pessoal no trabalho, critérios para diagnóstico do esgotamento } \\
\text { profissional. Há associação negativa entre esgotamento e satisfação no trabalho, idade e } \\
\text { tempo de docência. } \\
\text { A maior motivação para a docência foi a atualização e o aprendizado constantes } \\
\text { decorrentes da profissão. } \\
\text { As IES devem promover um trabalho mais prazeroso, valorizado, humanizado e menos } \\
\text { desgastante. }\end{array}$ \\
\hline 36 & $\begin{array}{l}\text { Treviso } \\
\text { (2015) }\end{array}$ & $\begin{array}{l}\text { Conhecer a percepção } \\
\text { sobre a formação, a } \\
\text { atuação e a satisfação } \\
\text { na atividade docente. }\end{array}$ & $\begin{array}{l}\text { Fatores que interferem facilitando ou dificultando a realização do trabalho de professor, } \\
\text { além de aspectos que impactam na sua satisfação, relacionados ao processo de ensino e } \\
\text { de aprendizagem, relações interpessoais, instituição de ensino superior, condições de } \\
\text { trabalho, além de questões pessoais do indivíduo professor. } \\
\text { As condições de trabalho no processo de ensino e aprendizagem foram apontadas como } \\
\text { fatores na IES que dificultam a prática docente. } \\
\text { As relações interpessoais foram apontadas como fatores que facilitam a prática docente } \\
\text { na IES. } \\
\text { O trabalho docente exige estudo, dedicação, domínio de saberes específicos e } \\
\text { pedagógicos, além de habilidades e competências para exercer a função docente. }\end{array}$ \\
\hline
\end{tabular}

IES: Instituição de Ensino Superior.

Há a necessidade de mais estudos sobre o tema, principalmente devido ao crescimento no número de IES no país: 851 em 1994, 2.314 em 2011 e 2.391 em 2013. Outro aspecto é que apenas $20 \%$ dos estudos apresentaram dados de IES privadas, sendo que o crescimento no quantitativo dessas instituições foi maior nos últimos anos: de 74,4\% em 1994 para $89,4 \%$ em 2011, com leve redução para $87,4 \%$ em $2013^{39,40,44,45}$.

Outro aspecto que merece destaque é a prevalência de docentes por sexo nas amostras observadas pelos estudos e nas IES nacionais. Quase a totalidade das pesquisas apresentou maioria de participantes mulheres, sendo que, na realidade brasileira, os homens representam aproximadamente $55 \%$ dos docentes que atuam nas IES ${ }^{41}$. Nesse sentido, há que se investigar se a maior participação feminina nos estudos decorre do aumento no número significativo de mulheres integradas ao mercado de trabalho nos últimos anos e/ou porque alguns cursos da saúde, tais como nutrição e enfermagem, são hegemonicamente femininos ${ }^{29,46,47}$. Há que se considerar também que homens e mulheres desempenham diferentes papéis sociais e tendem a ter diferentes necessidades e comportamentos, sendo as mulheres mais propensas à adaptação a multifunções ou tarefas profissionais e familiares ${ }^{29,48}$, o que pode contribuir para sua maior adesão e participação nas pesquisas.

Quanto ao regime de trabalho docente, enquanto nas IES públicas predominam os docentes que 
atuam em regime de tempo integral com dedicação exclusiva $(81,6 \%)$, nas IES privadas predominam os docentes com funções horistas $(39,9 \%)$ e o regime parcial $(35,2 \%)$; havendo apenas $24,9 \%$ de professores em regime integral ${ }^{41}$. Na presente revisão, embora a maioria dos estudos tenha sido realizado em IES Públicas, apenas 30\% apresentaram amostra composta majoritariamente por docentes em dedicação exclusiva.

Os docentes que atuam em regime de tempo integral e dedicação exclusiva expõem-se à sobrecarga pela necessidade de se envolver em pesquisa, ensino e extensão, além de atividades como participação de comissões, organização de eventos, ações administrativas, entre outras, exigidas destes professores ${ }^{22}$. Já os docentes horistas e os de regime parcial participam mais do ensino, pois o regime de trabalho dificulta seu envolvimento em atividades para além do exercício da docência ${ }^{47}$ e/ou podem sentir-se compelidos a se mostrarem participativos e "úteis" em suas IES; aspectos que merecem ser aprofundados em outros estudos.

O conjunto de estudos analisados nesta revisão não representa "uma amostra" que possa ser considerada representativa da realidade nacional, mas a análise conjunta das referências compiladas apresenta aspectos relevantes que contribuem para a compreensão dos aspectos envolvidos nos processos de saúde e doença de professores universitários da área da saúde.

As informações convergentes entre eles indicam que as condições objetivas e subjetivas de trabalho envolvidas nos processos de saúde e adoecimento podem ser categorizadas em três esferas: pessoal, social e institucional. Embora os professores de IES em geral estejam satisfeitos com a atividade realizada e com o ambiente de trabalho em que estão inseri$\operatorname{dos}^{8,21,22,24,26,32,36}$; há também uma grande parte dos docentes que sofre alguma espécie de exposição a riscos ou morbidades decorrentes do trabalho ${ }^{1,22,23,29,35}$.

Em geral, as vivências de prazer no trabalho foram associadas à identidade de ser professor, especialmente o reconhecimento do trabalho, a produção sistematizada de conhecimento e o impacto social que suas atividades promovem ${ }^{21,24,35}$, além da ampla possibilidade de interações e de fortalecimento dos laços afetivos do convívio social ${ }^{6,8,28,32}$. Não obstante, houve relatos, ainda que em menor frequência, referentes às relações, interações e vivências conflituosas entre alunos, professores e outros funcionários como aspectos negativos à saúde ${ }^{12,31,34}$. Nesse sentido, o sentimento de pertencimento, o respeito e a valorização profissional por parte de gestores, alunos e comunidade podem contribuir para a promoção da saúde docente ${ }^{22,36}$.
Em sua ampla maioria, os relatos de sofrimento por docentes de IES se referem à exaustão física e mental associadas à precarização das condições trabalho (tais como perda de direitos previdenciários, instabilidade contratual, aposentadorias precoces sem o devido provimento das vagas, competitividade acirrada por recursos e desvalorização do trabalho) e, consequente, aumento da carga laboral ${ }^{6,8}$. A precarização do trabalho ${ }^{1,6}$ e da infraestrutura ${ }^{22,24,30,32,34}$ gera insatisfação e apresenta repercussões na saúde dos professores e na qualidade do ensino superior.

Destacamos ainda que, embora a maioria dos estudos apontem que a satisfação dos professores nas relações interpessoais facilitam a prática docente ${ }^{6,28,31,36}$, podem existir mais aspectos desagradáveis do que agradáveis nas situações especificas de relação pessoal no trabalho ${ }^{12}$; e o ambiente físico de trabalho pode ser considerado aspecto de satisfação ${ }^{21,26}$, mas também de insatisfação, sendo deficitários de conforto e praticidade $\mathrm{e}^{1,8,22,24,32,49}$.

Os aspectos apontados expressam as contradições e ambiguidades do meio acadêmico onde o clima organizacional, as relações e os indivíduos compõem, conjuntamente, as fontes de satisfação, realização e sofrimento no trabalho, afetando diretamente o bem-estar, a saúde e a qualidade de vida dos docentes. Fontes de sofrimento, quando não resignificadas pelos sujeitos, podem gerar angústia, insatisfação e tensão, e aumentar o absenteísmo ${ }^{21,34}$, principalmente desencadeado por distúrbios psíquicos ${ }^{50}$.

Frente a essa realidade, refletir sobre a situação e os processos de saúde e adoecimento em professores universitários implica analisar os modelos de gestão implementados nas IES do país, que buscam maximizar a produtividade por meio da ampliação da razão do numero de alunos por professor e da quantidade de atividades desempenhadas por cada um no ensino, na pesquisa, na extensão e na administração ${ }^{51}$.

Políticas federais recentes como o Programa de Reestruturação e Expansão das Universidades Federais (REUNI) e o Plano Nacional de PósGraduação (2011-2020) da Coordenação de Aperfeiçoamento de Pessoal de Nível Superior (Capes), a despeito de contribuir valorosamente para a expansão e ampliação do acesso à educação superior e à pesquisa no Brasil, também agravaram a lógica de produção empresarial e a precarização do trabalho docente ${ }^{42,43}$.

Embora as relações de poder expressas por meio de hierarquias diretas sejam em geral mais sutis no ambiente universitário, as políticas vigentes que definem e cobram a produtividade mínima aceitável dos professores que atuam nas IES se embasam nos modelos econômico-político-culturais vigentes, 
geralmente quantificadas conforme o número de artigos, livros, dissertações e teses publicadas ${ }^{42}$, e parecem desconhecer o fato de que, a despeito de todo o esforço que empregam para serem "produtivos", professores (em especial os universitários) não são máquinas em competição para reduzir custos na confecção de produtos renováveis a intervalos de tempo cada vez menores ${ }^{5}$.

Em adição, a conjuntura de crise econômica, política e cultural vivida no país coloca em espera a continuidade dos planos de reestruturação e fortalecimento da educação e da ciência, intensificando a disputa pelos recursos escasseados ${ }^{52}$. A exacerbação da competitividade adiciona tensão à já extensa lista de demandas (no ensino, pesquisa, extensão e administração, somadas às atividades de planejamento e produção de conteúdo, além da negociação e estabelecimento de vínculos) desempenhadas pelos docentes de IES $^{29}$.

A tentativa de adequação do docente a essas características objetivas do trabalho tem promovido a fragmentação e o isolamento profissional que diminuem a qualidade da educação e agravam a frustração, o sofrimento e o adoecimento docente ${ }^{4,6}$. Tamanhas exigências laborais modificam também as relações e atividades desenvolvidas fora do trabalho, com consequentes impactos nas atividades de lazer, na convivência com familiares e amigos, e na qualidade de vida de todos os envolvidos ${ }^{8,53}$.

É importante destacar alguns estudos que apontam os docentes universitários como capazes de, ao enfrentar alguns dos obstáculos apontados, mobilizar os recursos disponíveis na busca de soluções criativas e colaborativas para tornar o trabalho possível e, ainda, obter resultados positivos no exercício da profissão ${ }^{6,12,28,54}$. O docente é capaz de desenvolver estratégias para lidar com as adversidades do ambiente e os ditames institucionais resgatando a função social de prazer e solidariedade nas relações de trabalho, por meio das transformações externas e internas que vá buscar ${ }^{8}$. Uma estratégia relevante é a busca de projetos profissionais alternativos que confiram valor, prazer e realização à atividade laboral ${ }^{6}$.

Nesse sentido, as horas adicionais de trabalho com a população parecem ser um aspecto característico do trabalho docente na área da saúde. É no decorrer desse processo que esses professores acabam por desenvolver relações com a comunidade local para analisar as necessidades sociais e constituírem as bases do que precisa ser ensinado, dando sentido e significado à sua prática ${ }^{9}$.

As interações sociais construídas nos diversos contextos do processo de ensino-aprendizagem e nas demais relações do cotidiano universitário favorecem de forma significativa a qualidade de vida e a saúde docente ${ }^{28}$. No entanto, em geral esse trabalho é computado como extensão, sendo pouco valorizado na econometria do trabalho acadêmico ${ }^{5}$, podendo resultar em frustração, exaustão, sofrimento e adoecimento $6,29,32,34,35,42$.

O docente envolvido na realidade social dos alunos e da comunidade, além de ator chave no processo de produção de saberes e práticas e na formação profissional, passa a representar um importante canal de comunicação e informação ao apresentar similaridade comunicativa e ainda servir de referência nos conhecimentos, comportamentos e atitudes em saúde s5-57. $^{\text {. }}$.

Como profissional da saúde, deve reconhecer a relevância da produção do cuidado para com a defesa e a afirmação da vida, por meio da qual é possível promover a saúde. Nesse processo, seu trabalho é peça fundamental para favorecer o empoderamento, a autonomia e a participação social (sua própria e da comunidade acadêmica) de forma a contribuir com a promoção da saúde individual e coletiva na $\mathrm{IES}^{9}$.

Esses aspectos nos aproximam dos conceitos de promoção da saúde ${ }^{58}$ e de ambientes de trabalho saudável, que destacam o papel dos indivíduos e das organizações na criação de oportunidades, escolhas e ambientes saudáveis ${ }^{59}$. O conceito moderno de promoção da saúde representa um modelo promissor para superar a perspectiva puramente preventiva e curativa, e para aprofundar a compreensão sobre a complexidade de se preservar os potenciais de saúde de indivíduos e grupos sociais de forma articulada às demais políticas e tecnologias de intervenção social que contribuem para a construção de ações que possibilitam responder às novas necessidades sociais em saúde $^{60,61}$. A saúde deve ser compreendida em seus múltiplos aspectos sem estar reduzida a qualquer de suas dimensões, seja ela biológica, psicológica, individual ou coletiva, objetiva ou subjetiva ${ }^{20}$.

As condições objetivas e subjetivas de trabalho que podem estar envolvidas nos processos de saúde e adoecimento docentes dialogam com os referenciais teóricos dos determinantes e condicionantes da saúde ${ }^{18}$. Não obstante, destacamos que as vivências pessoais e sociais são entendidas como produtos e produtoras do ambiente, das normas, da gestão e da organização do trabalho (aspectos institucionais $)^{62}$; podendo ou não ser ressignificadas pelos sujeitos ${ }^{6}$. Nesse sentido apontamos o marco conceitual das Universidades Promotoras de Saúde (UPS), onde as IES, enquanto espaço de interação social, devem aliar a vontade política à suficiência de recursos humanos, financeiros e estruturais de forma a melhorar a saúde e a qualidade de vida da comunidade universitária ${ }^{9,63}$. 
Aqui abrimos um parêntese para discutir o conceito de saúde empregado nos diversos estudos. Isso porque algumas publicações se destacam das demais ao investigar a saúde em sua concepção ampliada, na perspectiva da promoção da saúde, do bem-estar e da qualidade de vida, discutindo aspectos como: a integralidade, a singularidade, a humanização, a multidisciplinaridade, a interdisciplinaridade e a importância do diálogo e da escuta ${ }^{1,8,12,25,36}$.

Quando definem promoção da saúde como estratégia de produção social de saúde que apresenta um modo de pensar e de operar relativo à potencialização das capacidades individuais, coletivas e das comunidades em relação aos inúmeros condicionantes envolvidos nos processos saúde-doença-cuidado, reconhecem o sujeito empoderado como agente transformador da realidade ${ }^{64}$. Alguns estudos apontam, ainda, a necessidade da IES desenvolver uma gestão que priorize a promoção da saúde ${ }^{22}$ e a valorização dos docentes, a diminuição da carga de trabalho e a concretização digna do ensino, pesquisa e extensão, favorecendo sua missão de produção de conhecimento, valores e desenvolvimento humano ${ }^{23}$.

Outros estudos são mais sucintos ao apresentar algumas informações sobre saúde na perspectiva ampliada e favorável à qualidade de vida ${ }^{23,28-30}$, e outras publicações não fazem menção direta à saúde na perspectiva ampliada, mas apresentam visões de saúde atreladas à capacidade para o trabalho e o sentido de prazer e sofrimento no trabalho, bem como de condições estressoras e do aumento do risco de transtornos mentais $6,27,32$.

Não obstante, em alguns casos ainda persistem visões reducionistas e lineares centradas no binômio saúde-doença individual expressas tanto no desenho metodológico das pesquisas ${ }^{22,34}$, quanto no discurso de profissionais e/ou nas ações realizadas para intervir de forma pontual, assistencialista e curativista $^{31,33}$. Esses estudos não apresentam o processo saúde-doença como uma expressão populacional, cultural e espacial ${ }^{20}$, nem buscam identificar, em cada situação específica, as relações entre as condições de saúde e seus determinantes culturais, sociais e ambientais, dentro de ecossistemas modificados pelo trabalho e pela intervenção humana ${ }^{65}$. Mas, sim, tendem a colocar a responsabilidade pelo adoecimento e pelas ações de prevenção e controle sobre os indivíduos, reduzindo ou excluindo a dimensão social dos processos ${ }^{20}$.

Ressaltamos que a adoção de visões mais restritas de promoção da saúde não se relacionam diretamente a uma abordagem metodológica específica. Estudos com metodologias quanti-qualitativas, a despeito de serem indicadas de forma complementar para ampliar a compreensão do fenômeno ${ }^{66}$, muitas vezes ficaram restritos a informar prevalências e a discutir representatividades sem aprofundar em discussões epistemológicas ${ }^{34}$.

Essa discussão epistemológica se faz pertinente, uma vez que o desafio dos "docentes que cuidam enquanto ensinam" é continuar a ser um agente de transformação - onde a prática docente se torna um vetor importante nos processos de subjetivação dos sujeitos em formação e na potencialização de IES que invistam na promoção da saúde, tanto em sua perspectiva individual quanto coletiva ${ }^{8,28}$. Nesse sentido, as pesquisas científicas sobre saúde no trabalho devem compreender o ser humano como um ser singular e multidimensional que está inserido em um contexto real e concreto de trabalho ${ }^{62,67}$.

Embora a maior responsabilidade pela qualidade do ensino superior recaia sobre os professores e alunos, é mister lembrar que essa responsabilidade deve ser compartilhada com a IES, seus líderes, o governo, as associações e, enfim, toda a comunidade universitária deve se sentir compromissada e contribuir para o desenvolvimento de um ambiente favorável e de boas práticas no ensino superior ${ }^{68}$. São necessárias políticas que ajudem a reduzir a sobrecarga, mediante uma gestão que priorize melhorias nas condições de trabalho, incluindo recursos e fomentos para a concretização digna e a valorização do docente no ensino, na pesquisa e na extensão ${ }^{9}$.

Essa visão ampliada de Universidade Promotora de Saúde - onde os processos de promoção da saúde sejam contínuos e abranjam todas as áreas da instituição, incluindo docentes, pesquisadores, gestores e demais funcionários, estudantes e comunidade local, bem como instalações e estrutura organizacional devem permear as discussões e intervenções sobre o tema ${ }^{68}$. No entanto, nenhum dos estudos selecionados nesta revisão utiliza esse marco teórico para discutir ou recomendar iniciativas de superação dos problemas encontrados.

Diante dos aspectos apontados nesta revisão, percebemos a necessidade de compreender as relações mais amplas entre os determinantes ambientais da instituição, que influenciam as relações dentro e fora do ambiente de trabalho, e outros determinantes sociais do processo, tanto mais amplos (como política, economia e cultura), quanto mais individuais (como a família, o indivíduo e suas subjetividades) nos processos de saúde e adoecimento ${ }^{31}$.

Nessa direção, é preciso repensar o ser e fazer na área da docência em saúde, a fim de atender os princípios vigentes de promoção da saúde, bem como instigar novos referenciais capazes de repensar a saúde para além da dimensão biológica, objetiva e individual. As IES precisam superar a ideia assistencialista de saúde no trabalho, o que implica abarcar a 
integralidade do cuidado e do autocuidado além da perspectiva do docente como um ser integral e complexo inserido em um contexto de trabalho contraditório $^{67}$. Promover e cuidar da saúde de docentes implica reconhecer que diversos elementos, tais como a trajetória individual, os aspectos organizacionais, o ambiente e as relações sociais presentes nas instituições em que esses trabalhadores estão inseridos são fundamentais para a qualidade de vida e a saúde ${ }^{6,30}$.

Nessa perspectiva, pensar a saúde dos docentes da área da saúde é repensar o modelo de trabalho, de formação e de produção de conhecimentos nas IES de forma a ampliar as possibilidades interativas, além da articulação teoria, prática e ciência, por meio de debates e discussões que fortaleçam e divulguem o conceito de saúde segundo uma perspectiva ampliada ${ }^{67}$. Os docentes universitários da área da saúde precisam superar o modelo cartesiano de pensar ajudando a fortalecer os olhares complexos sobre as relações entre condições, ambientes e sujeitos, onde a compreensão dos processos de saúde e adoecimento é obtida a partir da dinâmica social que constitui o trabalho.

\section{Conclusões}

Docentes de IES desempenham diversas atividades profissionais que, sobrepostas e alinhadas ao modelo produtivista, acabam por representar fonte de sofrimento e angústia. Não obstante, a possibilidade de promover a saúde e ressignificar as relações humanas com o trabalho é fonte de prazer para o docente. Estratégias inovadoras, dinâmicas, ativas e participativas que atendam melhor às necessidades contemporâneas e complexas em educação e promoção da saúde devem ser maximizadas no ambiente universitário.

Para tal, as instituições devem ser capazes de fornecer estruturas, ambientes e políticas condizentes com a promoção da saúde, e o docente da área da saúde, como agente de saúde, não pode se portar como simples transmissor de conhecimento, e sim como um agente de transformação que deve estar engajado nesses processos por meio das suas atividades de ensino, pesquisa, extensão e administração. A interação entre condições objetivas e subjetivas de trabalho nas esferas pessoal, social e institucional é fundamental para minimizar as chances desse profissional de saúde se tornar um "curador adoecido".

São necessários estudos adicionais sobre o tema que favoreçam um olhar ampliado sobre fenômenos, e que possam suscitar a implantação e o monitoramento de políticas e programas efetivamente comprometidos com a promoção da saúde nas universidades.

\section{Contribuições de autoria}

Nogueira JAD orientou a pesquisa e Leite AF executou o levantamento das informações; ambas contribuíram na concepção do projeto, na análise das informações levantadas e na elaboração e aprovação final do artigo, e assumem total responsabilidade pela integridade e acurácia do trabalho realizado.

\section{Referências}

1. Lemos JC. Cargas psíquicas no trabalho e processos de saúde em professores universitários. Santa Catarina. Tese [Doutorado em Engenharia da Produção] Universidade Federal de Santa Catarina; 2005.

2. Bauman Z. Modernidade líquida. Rio de Janeiro: Jorge Zahar; 2001.

3. Campos GWS. Saúde paidéia. 2. ed. São Paulo: Hucitec; 2004.

4. Mancebo D, Rocha ML. Avaliação na educação superior e trabalho docente. Interações. 2002;7(13):55-75.

5. Luz MT. Prometeu acorrentado: análise sociológica da categoria produtividade e as condições atuais da vida acadêmica. Physis. 2005;15(1):39-57.

6. Coutinho MC, Magro MLPD, Budde C. Entre o prazer e o sofrimento: um estudo sobre os sentidos do trabalho para professores universitários. Psicol Teor Prat. 2011;13(2): 154-167.
7. Fernandes EC. Qualidade de vida no trabalho: como medir para melhorar. Salvador: Casa da Qualidade; 1996.

8. Garcia AL, Oliveira ER, Barros, EB. Qualidade de vida de professores do ensino superior na área da saúde: discurso e prática cotidiana. Cogitare Enferm. 2008;13(1):1-15.

9. Mello ALSF, Moysés ST, Moysés SJ. A universidade promotora de saúde e as mudanças na formação profissional. Interface. 2010;14(34):683-92.

10. Laurell AC, Noriega M. Processo de produção e saúde: trabalho e desgaste operário. São Paulo: Hucitec; 1989.

11. Dejours C. Conferências brasileiras: identidade, reconhecimento e transgressão no trabalho. São Paulo: FGV; 1999. 
12. Ulrich E. Percepção de professores universitários sobre as relações interprofissionais que levam a estresse. Santa Catarina. Dissertação [Mestrado em Psicologia] - Centro de Filosofia e Ciências Humanas da Universidade Federal de Santa Catarina; 2005.

13. Perim GL, Abdalla IG, Aguilar-da-Silva RH, Lampert JB, Stella RCR, Costa NMSC. Desenvolvimento docente e a formação de médicos. Rev Bras Educ Med. 2009;33(Supl 1):70-82.

14. Guba E, Lincoln Y. Avaliação de quarta geração. Campinas: Unicamp; 2011.

15. Jung CG. Memories, dreams, reflections. Rio de Janeiro: Nova Fronteira; 1989.

16. Mendes KDS, Silveira RCCP, Galvão CM. Revisão integrativa: método de pesquisa para a incorporação de evidências na saúde e na enfermagem. Texto Context Enferm. 2008;17(4):758-64.

17. Ministério da Saúde (Brasil). Resolução No 287 de 08 de Outubro de 1998. Diário Oficial da União 7 maio 1998;Seção 1.

18. Buss PM, Filho AP. A saúde e seus determinantes sociais. Physis. 2007;17(1):77-93.

19. Cunha GT, Campos GWS. Apoio matricial e atenção primária em saúde. Saude Soc. 2011;20(4):961-70.

20. Batistella C. Abordagens contemporâneas do conceito de saúde. In. Fonseca AF, Corbo AMD. O território e o processo saúde-doença. Rio de Janeiro: EPSJV; Fiocruz; 2007. p. 51-86.

21. Marqueze EC, Moreno CRC. Satisfação no trabalho e capacidade para o trabalho entre docentes universitários. Psicol Estud. 2009;14(1):75-82.

22. Fontana RT, Pinheiro DA. Condições de saúde auto-referidas de professores de uma universidade regional. Rev Gaúcha Enferm. 2010;31(2):270-6.

23. Servilha EAM, Arbach MP. Queixas de saúde em professores universitários e sua relação com fatores de risco presentes na organização do trabalho. Disturb Comum. 2011;23(2):181-91.

24. Ferreira ACM. Satisfação no trabalho de docentes de uma instituição pública de ensino superior: reflexos na qualidade de vida. Goiás. Dissertação [Mestrado em Enfermagem] - Universidade Federal de Goiás; 2011.

25. Santos GB. Bem-estar e condições de trabalho de professores do Centro de Ciências da Saúde da Universidade Federal de Pernambuco. Pernambuco. Dissertação [Mestrado em Saúde Coletiva] - Centro de Ciências da Saúde da Universidade Federal de Pernambuco; 2013.

26. Priess, F. Características do estilo de vida e da qualidade de vida dos professores universitários de instituições privadas de Foz do Iguaçu e região. Paraná. Dissertação [Mestrado em Educação Física ] - Universidade Federal do Paraná; 2012.

27. Ferreira RC, Silveira AP, Barbosa MAS, Feres SB, Souza JGS, Martins AMEB. Transtorno mental e estressores no trabalho entre professores universitário da área da saúde. Trab Educ Saúde. 2015;13(Supl 1):135-55.

28. Silvério MR, Patrício ZM, Brodbeck IM, Grosseman S. O ensino na área da saúde e sua repercussão na qualidade de vida docente. Rev Bras Educ Med. 2010;34(1):65-73.

29. Oliveira ERA, Garcia AL, Gomes MJ, Bittar TO, Pereira AC. Gênero e qualidade de vida percebida: estudo com professores da área de saúde. Ciênc Saúde Coletiva. 2012;17(3):741-47.

30. Rohde CLC. Qualidade de vida no trabalho sob a perspectiva de professores de ensino superior. Santa Maria. Dissertação [Mestrado em Psicologia] - Universidade Federal de Santa Maria; 2012.

31. Lago RR, Cunha BS, Borges MFSO. Percepção do trabalho docente em uma universidade da região Norte do Brasil. Trab Educ Saúde. 2015;13(2):429-50.

32. Gonçalves ASR, Pires DEP. O trabalho de docentes universitários da saúde: situações geradoras de prazer e sofrimento. Rev Enferm UERJ. 2015;23(2):266-71.

33. Santos NP, Marinho FP, Lima KYN, Rodrigues CCFM, Santos VEP. Docência universitária e o estresse: estressores nos cursos de enfermagem e medicina. Rev Enferm UFSM. 2016;6(1):61-70.

34. Lima MFEM, Lima-Filho DO. Condições de trabalho e saúde do/a professor/a universitário/a. Ciênc Cogn. 2009;14(3):62-82.

35. Dallacosta FM. Avaliação do nível de satisfação no trabalho e dos sintomas de Burnout em docentes da área da saúde. Porto Alegre. Tese [Doutorado em Medicina ] - Faculdade de Medicina da Pontifícia Universidade Católica do Rio Grande do Sul; 2014.

36. Treviso P. Percepção de profissionais da área da saúde sobre a formação, atuação e satisfação em sua atividade docente. Porto Alegre. Tese [Doutorado em Medicina e Ciências da Saúde] - Pontifícia Universidade Católica do Rio Grande do Sul; 2014.

37. Ministério da Educação. O Plano de desenvolvimento da educação: razões, princípios e programas. Caderno de Pesquisa. 2008;38:1-43.

38. Oliveira A. Diretrizes gerais do programa de apoio a planos de Reestruturação e Expansão das Universidades Federais (REUNI). Rev Gest. 2008;4.

39. Conselho Nacional de Educação. Censo da educação superior 2013: resumo técnico. Brasília, DF: Instituto Nacional de Estudos e Pesquisas Educacionais Anísio Teixeira (Inep); 2015.

40. Brasil. Projeto CNE/Unesco 914BRZ1142.3: Desenvolvimento, aprimoramento e consolidação de uma educação nacional de qualidade. Brasília, DF; 2013.

41. Ministério da Educação. Censo da Educação Superior 2003. Brasília, DF; 2004.

42. Mancebo D, Silva Júnior. JR (Org.). Trabalho docente e expansão da educação superior brasileira. Rio de Janeiro: EdUERJ; 2012. 
43. Brasil. Ministério da Educação. O que é REUNI [internet]. REUNI 25 mar 2010. [acesso em 6 set 2015]. Disponível em: http://reuni.mec.gov.br/oque-e-o-reuni

44. Brasil. Evolução das estatísticas do ensino superior no Brasil: 1980-1996. [internet] Brasília, DF: Sediae/Inep/MEC; 1996. [acesso em 4 abr 2011]. Disponível em: http://bit.ly/2p9VSi6

45. Brasil. Ministério da Educação. Sinopses estatísticas da educação superior: graduação. [internet]. Brasília, DF: Inep; 2011. [acesso em 4 abr 2016]. Disponível em: http://portal.inep.gov.br/ sinopses-estatisticas-da-educacao-superior

46. Gomes JH, Caetano JCR. Educação a distância, democracia e sustentabilidade. Jequié/Lisboa: Associação Brasileira de Educação a Distância; 2014. 11p.

47. Rocha KB, Sarriera JC. Saúde percebida em professores universitários: gênero, religião e condições de trabalho. Psicol Esc Educ. 2006;10(2):187-96.

48. Ludermir AB. Inserção produtiva, gênero e saúde mental. Cad Saúde Pública. 2000;16(3):647-59.

49. Departamento Intersindical de Estudos e Pesquisas de Saúde e dos Ambientes de Trabalho. Condições de trabalho e saúde dos trabalhadores do ensino privado no estado do Rio Grande do Sul [Internet]. São Paulo: Diesat; 2009. Disponível em: http://bit. ly/2ogSWTh

50. Gasparini SM, Barreto SM, Assunção AÁ. O professor, as condições de trabalho e os efeitos sobre sua saúde. Educação e Pesquisa. 2005;31(2):189-99.

51. Ministério da Educação. Fundação Capes. História e missão [Internet]. Brasília, DF; 2008. [acesso em 2 de mar 2016] Disponível em: http://bit.ly/1pLoXJX

52. Gadotti M. Perspectivas atuais da educação. São Paulo Perspec. 2000;14(2):3-11.

53. Pachane GG, Vitorino BM. A Expansão do ensino superior no Brasil pelo programa REUNI: democratização da formação universitária ou apenas uma ambivalência legal? Poiésis. 2015;9(16):438-56. Disponível em: http://bit.ly/2nSTNqx

54. Santos GB. A fênix renasce das cinzas: os professores e seus mecanismos de fuga e enfrentamento. [Apresentação no VI Seminário da Redestrado: Regulação Educacional e Trabalho Docente; 2006 nov 6-7; Rio de Janeiro, Brasil]. Disponível em: http://bit.ly/2pa80iP

55. Chickering AW, Gamson ZF. Seven principles for good practice in undergraduate education. AAHEA Bulletin. 1987;39(7):3-7.
56. Borges TT, Rombaldi AJ, Knuth AG, Hallal PC. Conhecimento sobre fatores de risco para doenças crônicas: estudo de base populacional. Cad Saúde Pública. 2009;25(7). [acesso 20 abr 2016] Disponível em: http://bit.ly/2oRpb9Q

57. Oliveira LM. Promoção da saúde na educação física escolar: concepções e propostas na perspectiva de professores do ensino público estadual da região Centro-Oeste do município de São Paulo. Motriz Revista de Educação Física. 2010;16(2):535. [acesso 20 abr 2016]. Disponível em: https://goo.gl/57w2CJ

58. Sicoli JL, Nascimento PR. Promoção de saúde: concepções, princípios e operacionalização. Interface. 2003;7(12):101-22.

59. Organização Mundial da Saúde. Carta de Ottawa para la promoción de la salud. In: Organización Panamericana de la Salud. Promoción de la salud: una antologia. Washington, DC: OPAS; 1996. p. 367-72.

60. Brasil. Ministério da Saúde. Secretaria de Vigilância em Saúde. Epidemiologia e Serviços de Saúde: Revista do Sistema Único de Saúde do Brasil. 2012;21(3).

61. Brasil. Ministério da Saúde. Política Nacional de Promoção da Saúde: Revisão da Portaria MS/GM n ${ }^{\circ}$ 687, de 30 de março de 2006. Brasília, DF; 2015.

62. Dejours C. A loucura do trabalho: estudo de psicopatologia do trabalho. São Paulo: Cortez; 1987.

63. Rocha E. Universidades promotoras de saúde. Rev Port Cardiol. 2008;27(1):29-35.

64. Backes MTS, Rosa LM, Fernandes GCM, Becker SG, Meirelles BHS, Santos SMA. Conceitos de saúde e doença ao longo da história sob o olhar epidemiológico e antropológico. Rev Enferm. 2009;17(1):111-7.

65. Minayo MCS, Miranda AC. Saúde e ambiente sustentável: estreitando nós. Rio de Janeiro: Fiocruz; 2002.

66. Minayo MCS, Sanches O. Quantitativo-Qualitativo: oposição ou complementaridade? Cad Saúde Pública. 1993;9(3): 239-62.

67. Dalmolin BB, Backes DS, Zamberlan C, Schaurich D, Colomé JS, Gehlen MH. Significados do conceito de saúde na perspectiva de docentes da área da saúde. Esc Anna Nery. 2011;15(2):389-94.

68. Silva A, Brito I. Instituições de ensino superior promotoras de saúde. In: Pedroso R, Brito I (Ed.). Saúde dos estudantes do ensino superior de enfermagem: estudo de contexto na Escola Superior de Enfermagem de Coimbra. Série Monográfica Educação e Investigação em Saúde. 2014;12:17-31. 